\title{
Rigidifying Effect of Metal-Organic Frameworks: Protect the Conformation, Packing Mode and Blue Fluorescence of a Soft Piezofluorochromic Compound under Pressures up to $8 \mathrm{MPa}$
}

Zhang-Wen Wei, Cheng-Xia Chen, Shao-Ping Zheng, Hai-Ping Wang, Ya-Nan Fan, Ye-Ye Ai, Mei Pan*, Cheng-Yong Su*

MOE Laboratory of Bioinorganic and Synthetic Chemistry, Lehn Institute of Functional Materials, School of Chemistry and Chemical Engineering, Sun Yat-Sen University, Guangzhou 510275, China

* To whom correspondence should be addressed.

Email: Prof. Mei Pan: panm@mail.sysu.edu.cn; Prof. Cheng-Yong Su, cesscy@mail.sysu.edu.cn 


\section{Table of Contents}

S1. Chemicals and Instruments ................................................................................ 3

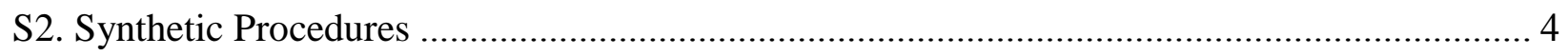

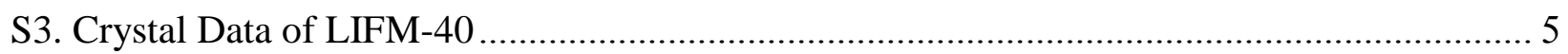

S4. Powder X-ray diffraction patterns (PXRD), UV-vis and fluorescence spectra of LIFM-40... 6

S5. Photos, CIE Coordinates of LIFM-40 and TABD-COOH ligand and Quantum Yield after

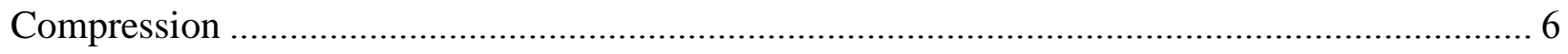

S6. Thermogravimetric Analysis (TGA) and Variable-temperature-dependent Power X-ray

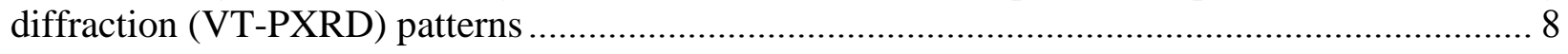

S7. Density Functional Theory (DFT) Computations........................................................ 9

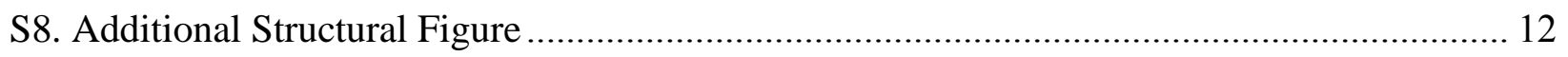

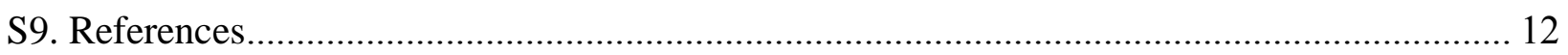




\section{S1. Chemicals and Instruments}

Ethynylbenzene and 4-(methoxycarbonyl)phenylboronic acid were purchased from Bide Pharmatch Ltd. Copper (II) bromide was bought from Sinopharm Chemical Reagent Co., Ltd. Dichloromethane was purchased from Guangdong Guanghua Sci-Tech Co., Ltd. Palladium(II) chloride was purchased from Kun Ming Boren Precious Metals Co., Ltd. Toluene, potassium carbonate, anhydrous calcium chloride, N,N-dimethylformamide (DMF) and acetone were bought from Guangzhou Chemical Reagent Factory. 2-Methoxyethanol (DME) was from Aladdin. Tetrakis(triphenylphosphine)palladium was purchased from Beijing InnoChem Science $\&$ Technology Co., Ltd. All commercial chemicals were used without further purification unless otherwise mentioned.

Nuclear magnetic resonance (NMR) data was acquired on a $400 \mathrm{MHz}$ Nuclear Magnetic Resonance Spectrometer. Single crystal X-ray diffraction data was collected on a Agilent Technologies SuperNova X-RAY diffractometer system equipped with a $\mathrm{Cu}$ sealed tube $(\lambda=$ 1.54178 ) at $40 \mathrm{kV}$ and $30 \mathrm{~mA}$. Powder X-ray diffraction (PXRD) patterns and variabletemperature-dependent PXRD patterns were recorded on a Rigaku SmartLab diffractometer (Bragg-Brentano geometry, $\mathrm{Cu} \mathrm{K \alpha l}$ radiation, $\lambda=1.54056 \AA$ ). Thermogravimetric analysis (TGA) was performed on a NETZSCH STA 449 F3 Jupiter system in nitrogen and under 1 atm of pressure at a heating rate of $10{ }^{\circ} \mathrm{C} \mathrm{min}{ }^{-1}$. Elemental analyses were performed on an Elementar Vario EL Cube. UV-Vis absorption spectra were recorded using a Shimadzu UV-2450 spectrophotometer. Photoluminescence spectra, lifetime and quantum yield data were collected on EDINBURGH FLS908 spectrophotometer. The absolute quantum yields for fluorescence emission (400 to $800 \mathrm{~nm}$ ) were measured with a quartz sample holder in an integrating sphere attached to the EDINBURGA FLS980 spectrophotometer. The overall quantum yield $\Phi$ is calculated by

$$
\Phi=\frac{S(\mathrm{Em})}{S(\mathrm{Abs})}=\frac{\int \frac{\lambda}{h c}\left[I_{\mathrm{sample}(\mathrm{em})}(\lambda)-I_{\text {reference }(\mathrm{em})}(\lambda)\right] \mathrm{d} \lambda}{\int \frac{\lambda}{h c}\left[I_{\mathrm{sample}(\mathrm{ex})}(\lambda)-I_{\text {reference }(\mathrm{ex})}(\lambda)\right] \mathrm{d} \lambda}
$$

Where $S(\mathrm{Em})$ means the number of photons emitted from the sample; $S(\mathrm{Abs})$ means the number of photons absorbed by the sample; $\lambda$ means the wavelength; $h$ means Planck's constant; $c$ means the velocity of light; $I_{\text {sample(em) }}$ and $I_{\text {reference(em) }}$ mean the photoluminescence intensities with and without the sample, respectively; $I_{\text {sample(ex) }}$ and $I_{\text {reference(ex) }}$ mean the integrated intensities of excitation light with and without a sample, respectively. 


\section{S2. Synthetic Procedures}

A. Ligand Synthesis

The 4,4'-((Z,Z)-1,4-diphenylbuta-1,3-diene-1,4-diyl)dibenzoic acid (TABD-COOH) was synthesized according to the reported reference. ${ }^{1}$

\section{B. MOF Synthesis}

In a $5 \mathrm{~mL}$ Pyrex vial, anhydrous $\mathrm{CaCl}_{2}(9.4 \mathrm{mg}, 0.085 \mathrm{mmol}, 2.125$ equiv), TABD-COOH (18 $\mathrm{mg}, 0.040 \mathrm{mmol}, 1$ equiv) and trifluoric acetic acid $(8 \mu \mathrm{L})$ were ultrasonically dissolved in DMF $(1.8 \mathrm{~mL})$. The mixture was heated in an oven kept at $100{ }^{\circ} \mathrm{C}$ for $48 \mathrm{~h}$. After cooling to room temperature, colorless single crystals suitable for X-ray structure determination were obtained. Fresh crystals was soaked in Methanol for two days, and then dried under vacuum at 100 degree to get fully activated sample. $\mathrm{Ca}\left(\mathrm{C}_{30} \mathrm{H}_{20} \mathrm{O}_{4}\right)$, Anal. Calcd (\%): C, 74.36; H, 4.16. Found: C, 74.02; H, 3.98. 


\section{S3. Crystal Data of LIFM-40}

Single crystal X-ray diffraction data was measured on an Agilent Technologies SuperNova XRAY diffractometer system equipped with a $\mathrm{Cu}$ sealed tube $(\lambda=1.54178 \AA)$ at $40 \mathrm{kV}$ and $30 \mathrm{~mA}$. The structure was solved by direct method and refined by full-matrix least-squares on $F^{2}$ using SHELXTL. ${ }^{2}$ All non-hydrogen atoms were refined with anisotropic displacement parameters during the final cycles. Organic hydrogen atoms were placed in calculated positions with isotropic displacement parameters set to $1.2 \times \mathrm{U}_{\mathrm{eq}}$ of the attached atom. The flack value is 0.51 indicating that the crystal is racemic twinning. TWIN was used to refine the structure and the final flack value is 0 . Crystal data are summarized in Table S1.

Table S1. Crystal Data for LIFM-40.

\begin{tabular}{|c|c|c|}
\hline Formula & $\mathrm{C}_{36} \mathrm{H}_{34} \mathrm{O}_{6} \mathrm{~N}_{2} \mathrm{Ca}$ & \\
\hline CCDC No. & 1454887 & \\
\hline Fw & 630.73 & \\
\hline Color/Shape & Colorless/Plate & \\
\hline Crystal size $\left(\mathrm{mm}^{3}\right)$ & $0.20 \times 0.20 \times 0.10$ & \\
\hline Crystal system & Orthorhombic & \\
\hline Space group & $P 2_{1} 2_{1} 2_{1}$ & \\
\hline \multirow[t]{3}{*}{ Unit cell dimensions } & $a=8.9836(2) \AA$ & $\alpha=90^{\circ}$ \\
\hline & $\mathrm{b}=10.5198(4) \AA$ & $\beta=90^{\circ}$ \\
\hline & $b=32.7196(14) \AA$ & $\gamma=90^{\circ}$ \\
\hline$V\left(\AA^{3}\right)$ & $3113.35(19)$ & \\
\hline$Z$ & 4 & \\
\hline$d_{\text {calc. }}\left(\mathrm{g} / \mathrm{cm}^{3}\right)$ & 1.346 & \\
\hline$\mu\left(\mathrm{mm}^{-1}\right)$ & 2.149 & \\
\hline$T(\mathrm{~K})$ & $298(2)$ & \\
\hline$F(000)$ & 1328 & \\
\hline Reflns collected & 8611 & \\
\hline Independent reflns & 4618 & \\
\hline Obsd data $[I>2 \sigma(I)]$ & 4261 & \\
\hline Data/restraints/parameters & 4618 / 56 / 409 & \\
\hline Completeness & $97 \%$ & \\
\hline GOF on $F^{2}$ & 1.087 & \\
\hline$R_{\text {int }}$ & 0.0329 & \\
\hline$R_{1}, w R_{2}[I>2 \sigma(I)]$ & $0.0897,0.2369$ & \\
\hline$R_{1}, w R_{2}$ (all data) & $0.0950,0.2422$ & \\
\hline$\Delta \rho_{\max } / \Delta \rho_{\min }\left[\mathrm{e} \cdot \AA^{-3}\right]$ & $1.02 /-0.65$ & \\
\hline
\end{tabular}


S4. Powder X-ray diffraction patterns (PXRD), UV-vis and fluorescence spectra of LIFM-40.
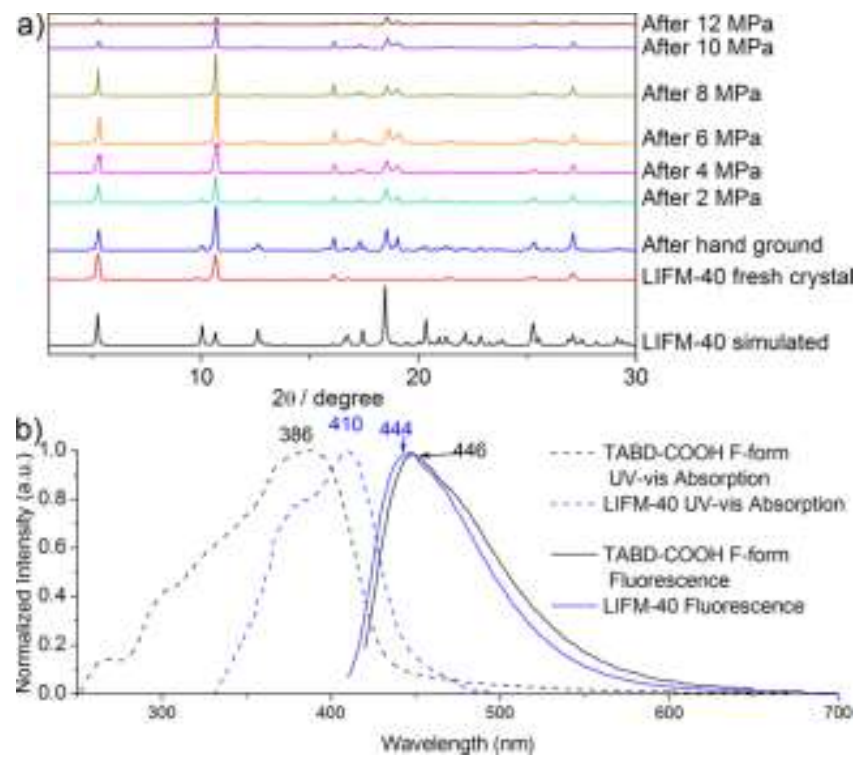

Figure S1. (a) PXRD patterns of LIFM-40 samples; (b) solid-state UV-Vis absorption (via diffuse reflectance) and fluorescence emission spectra of TABD-COOH F-form and LIFM-40.

S5. Photos, CIE Coordinates of LIFM-40 and TABD-COOH ligand and Quantum Yield after Compression

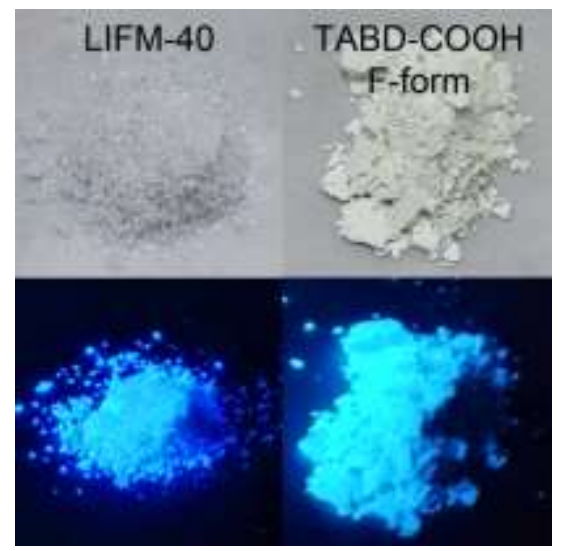

Figure S2. Photos of LIFM-40 and TABD-COOH F-form under day light and $365 \mathrm{~nm}$ UV light, respectively. 


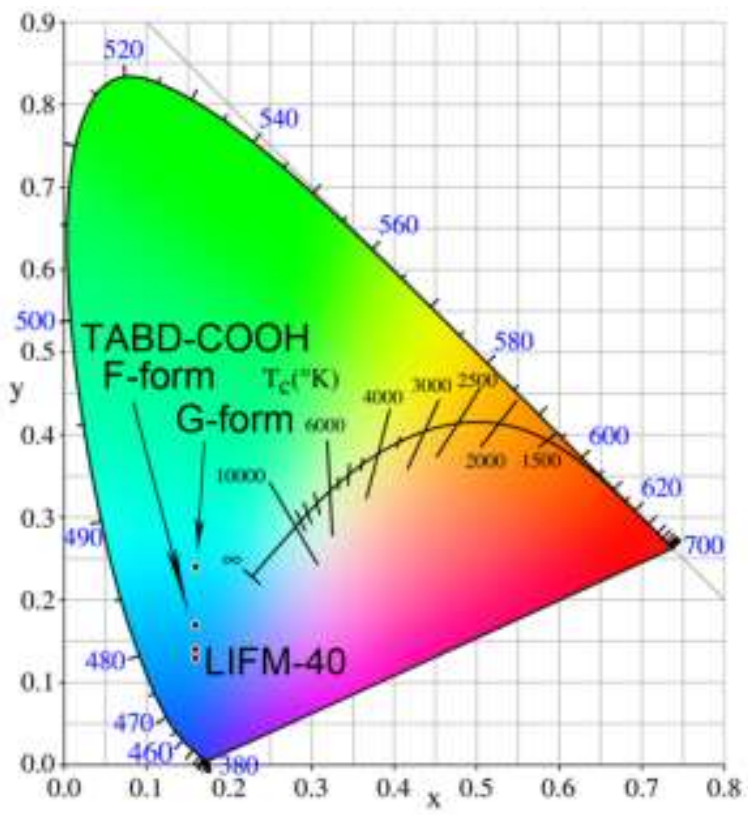

Figure S3. The CIE color space chromaticity diagram of LIFM-40 samples and TABD-COOH samples.

Table S2. The CIE color space chromaticity diagram of fresh LIFM-40, crushed LIFM-40, TABD-COOH F-form and TABD-COOH G-form.

\begin{tabular}{lrr}
\hline Samples & $\mathrm{x}$ & $\mathrm{y}$ \\
\hline LIFM-40 fresh crystal & 0.16 & 0.14 \\
LIFM-40 after hand ground & 0.16 & 0.14 \\
LIFM-40 after 2MPa & 0.16 & 0.13 \\
LIFM-40 after 4MPa & 0.16 & 0.14 \\
LIFM-40 after 6MPa & 0.16 & 0.14 \\
LIFM-40 after 8MPa & 0.16 & 0.13 \\
LIFM-40 after 10MPa & 0.16 & 0.13 \\
LIFM-40 after 12MPa & 0.16 & 0.13 \\
TABD-COOH F-form & 0.16 & 0.17 \\
TABD-COOH G-form & 0.16 & 0.24 \\
\hline
\end{tabular}




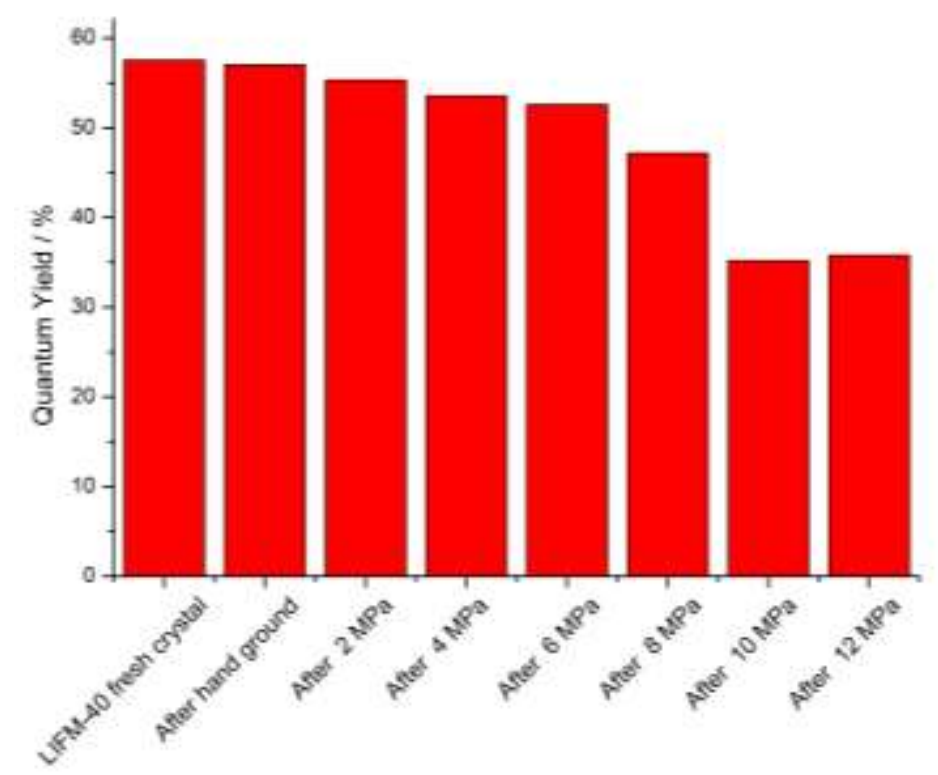

Figure S4. The quantum yield of LIFM-40 samples after compressions.

S6. Thermogravimetric Analysis (TGA) and Variable-temperature-dependent Power X-ray diffraction (VT-PXRD) patterns

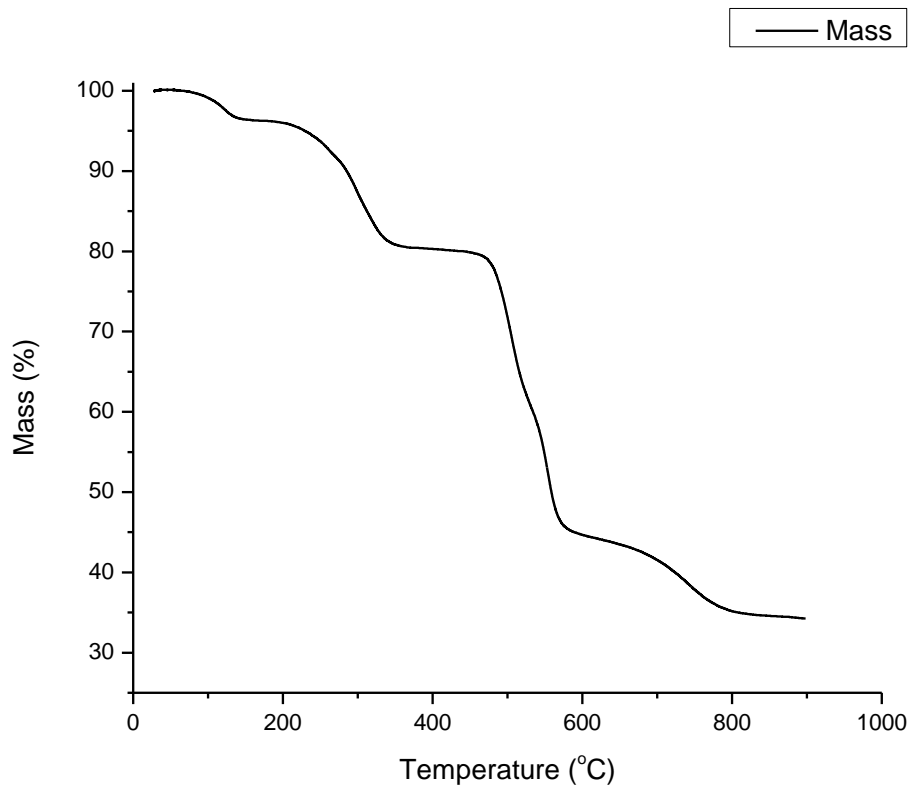

Figure S5. TGA curves of LIFM-40 fresh sample. The decomposition started from around $200{ }^{\circ} \mathrm{C}$. 


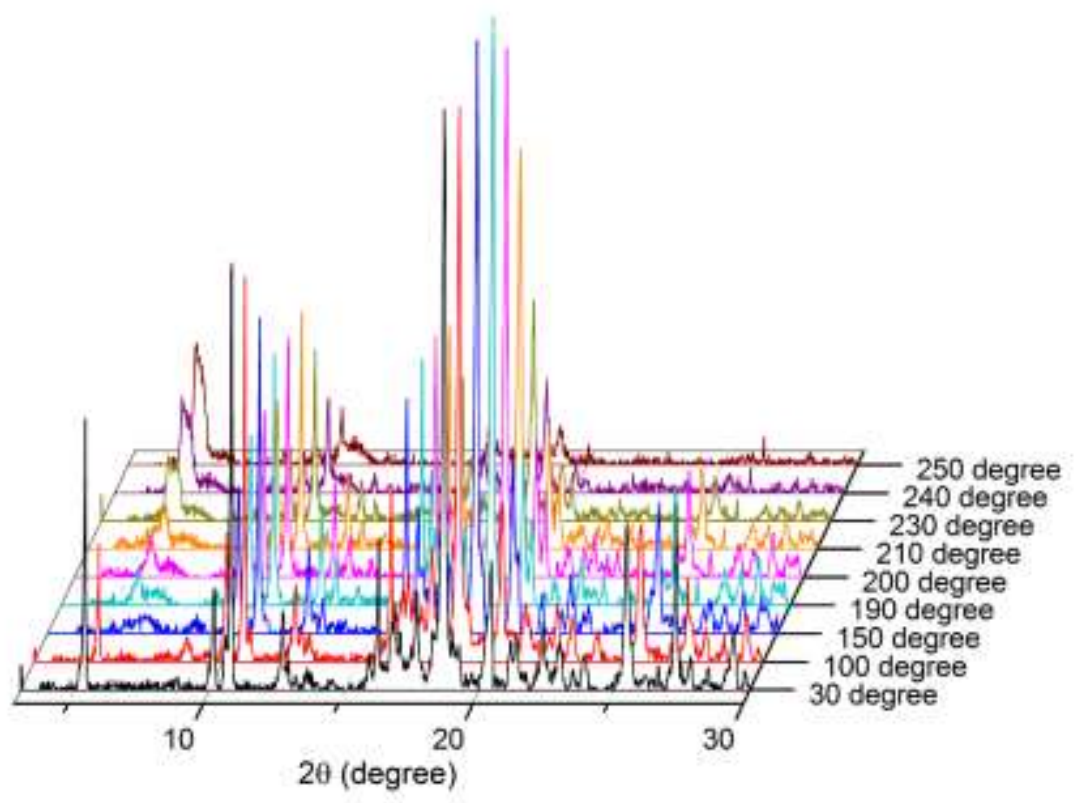

Figure S6. Variable-temperature-dependent PXRD patterns of LIFM-40.

\section{S7. Density Functional Theory (DFT) Computations}

The DFT calculations were carried out with Gaussian 09 program using B3LYP/SDD basis sets with the help of Gaussview program. ${ }^{3,4}$

For discussion convenience, we define 5 planes and 2 bond angle (Figure S7). P1 is the average plane of the four $\mathrm{C}$ atoms forming two $\mathrm{C}=\mathrm{C}$ double bond; $\mathrm{P} 2$ and $\mathrm{P} 4$ is the average plane of the phenyl ring without carboxylate group; P3 and P5 is the average plane of the phenyl ring connecting to carboxylate group. Thus dihedral angles $<\mathrm{P} 1-\mathrm{P} 2,<\mathrm{P} 1-\mathrm{P} 3,<\mathrm{P} 1-\mathrm{P} 4$, and $<\mathrm{P} 1-\mathrm{P} 5$ are defined. And $<1$ and $<2$ is the bond angle of the $\mathrm{C}$ atom connecting with two phenyl rings. The optimized molecular conformations are obtained by fixing the dihedral angles and bond angles including $<\mathrm{P} 1-\mathrm{P} 2,<\mathrm{P} 1-\mathrm{P} 3,<\mathrm{P} 1-\mathrm{P} 4,<\mathrm{P} 1-\mathrm{P} 5,<1$ and $<2$ then relax all the atoms. The energies, and vibrational wave numbers of the optimized conformations were calculated. The absences of imaginary wavenumbers confirmed that the structures correspond to minimum energy. Then TDDFT calculations were performed to obtain the simulated UV-Vis spectrum and HOMO/LUMO energies. The calculated results are summarized in Table S3. The comparison of the simulated UV-Vis spectra is in Figure S8. 


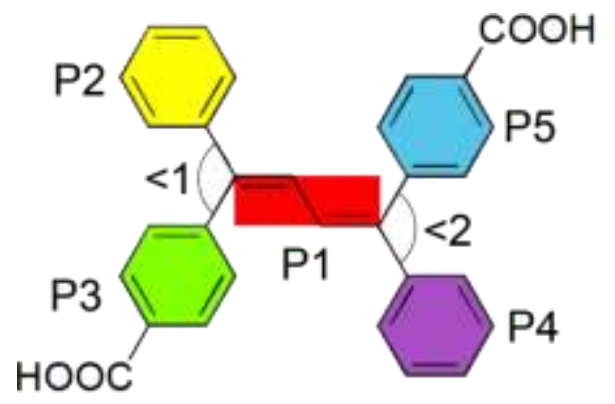

Figure S7. The definition of the planes and angles for discussion.

Table S3. Computational results of TABD-COOH in F-form conformation and LIFM-40 conformation, respectively.

\begin{tabular}{|c|c|c|}
\hline & $\begin{array}{c}\text { TABD-COOH in F-form } \\
\text { Conformation }\end{array}$ & $\begin{array}{c}\text { TABD-COOH in LIFM-40 } \\
\text { Conformation }\end{array}$ \\
\hline Total Energy (Ha) & -1457.14283947 & -1457.15097550 \\
\hline Zero Point Vibrational Energy $\left(\mathrm{kcal} \mathrm{mol}^{-1}\right)$ & 277.28633 & 11.50 \\
\hline First Vibrational Frequency $\left(\mathrm{cm}^{-1}\right)$ & 8.75 & -0.20741 \\
\hline HOMO Energy $(\mathrm{Ha})$ & -0.20815 & -0.08835 \\
\hline LUMO Energy $(\mathrm{Ha})$ & -0.08339 & 0.11906 \\
\hline HOMO-LUMO Gap (Ha / $\mathrm{nm})$ & 0.12476 & \\
\hline
\end{tabular}




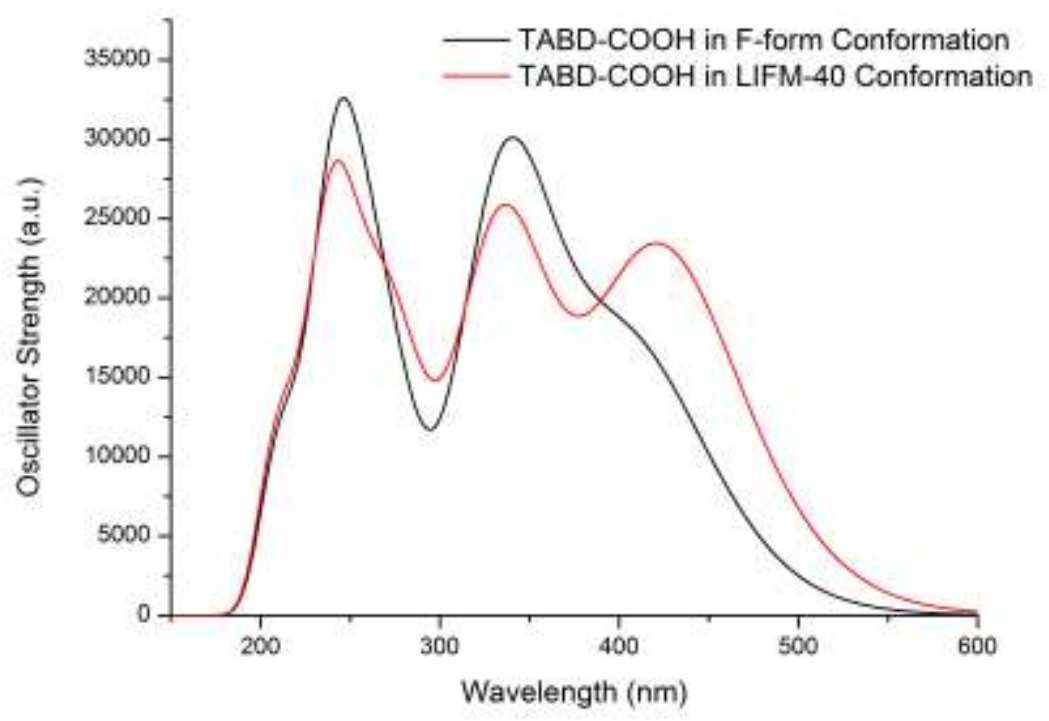

Figure S8. Simulated UV-Vis spectra of TABD-COOH in F-form and LIFM-40 conformations. 


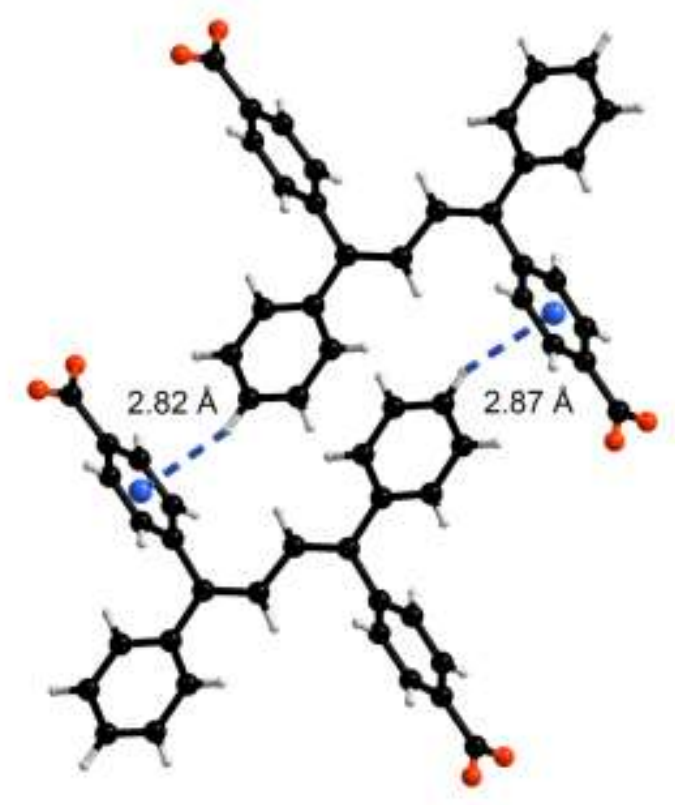

Figure S9. The $\mathrm{C}-\mathrm{H} \cdots \pi$ interaction in LIFM-40.

\section{S9. References}

(1) Han, T.; Zhang, Y.; Feng, X.; Lin, Z.; Tong, B.; Shi, J.; Zhi, J.; Dong, Y. Chem. Commun. 2013, 49, 7049 .

(2) Spek, A. J. Appl. Crystallogr. 2003, 36, 7.

(3) Dennington, R.; Keith, T.; Millam, J.; Semichem Inc.: Shawnee Mission, KS, 2009.

(4) Frisch, M. J.; Trucks, G. W.; Schlegel, H. B.; Scuseria, G. E.; Robb, M. A.; Cheeseman, J. R.; Scalmani, G.; Barone, V.; Mennucci, B.; Petersson, G. A.; Nakatsuji, H.; Caricato, M.; Li, X.; Hratchian, H. P.; Izmaylov, A. F.; Bloino, J.; Zheng, G. L.; Sonnenberg, J. L.; Hada, M.; Ehara, M.; Toyota, K.; Fukuda, R.; Hasegawa, J.; Ishida, M.; Nakajima, T.; Honda, Y.; Kitao, O.; Nakai, H.; Vreven, T.; Montgomery, J. A.; Jr.; Peralta, J. E.; Ogliaro, F.; Bearpark, M.; Heyd, J. J.; Brothers, E.; Kudin, K. N.; Staroverov, V. N.; Keith, T.; Kobayashi, R.; Normand, J.; Raghavachari, K.; Rendell, A.; Burant, J. C.; Iyengar, S. S.; Tomasi, J.; Cossi, M.; Rega, N.; Millam, J. M.; Klene, M.; Knox, J. E.; Cross, J. B.; Bakken, V.; Adamo, C.; Jaramillo, J.; Gomperts, R.; Stratmann, R. E.; Yazyev, O.; Austin, A. J.; Cammi, R.; Pomelli, C.; Ochterski, J. W.; Martin, R. L.; Morokuma, K.; Zakrzewski, V. G.; Voth, G. A.; Salvador, P.; Dannenberg, J. J.; Dapprich, S.; Daniels, A. D.; Farkas, O.; Foresman, J. B.; Ortiz, J. V.; Cioslowski, J.; Fox, D. J.; Gaussian, Inc.: Wallingford CT, 2010. 